\title{
Rethinking Quality Improvement in Athletic Health Care
}

\author{
Matthew J. Rivera, DAT, LAT, ATC \& Kenneth E. Games, PhD, LAT, ATC
}

Indiana State University, Terre Haute, IN

\section{Key Phrases}

Continuous Improvement, systems-level, individual process improvement

\section{Correspondence}

Dr. Matthew Rivera, Indiana State University, 567 N. 5th Street, Terre Haute, IN 47809.

Email: Matthew.Rivera@indstate.edu

Twitter: @Matt_RiveraDAT

\section{Full Citation}

Rivera MJ \& Games KE. Rethinking quality improvement in athletic health care. Clin Pract Athl Train. 2020;3(2): 3-5.

https://doi.org/10.31622/2020/0002.2.

\section{EDITORIAL}

The concept of continuous quality improvement (CQI) has gained more recognition within the profession of athletic training in recent years. With the new transition into the professional-level master's degree and the Commission on Accreditation of Athletic Training Education standards related to quality assurance in health care, it is no surprise that we are starting to talk about CQI more seriously. The purpose of this editorial is to speak frankly to our audience about how potentially unattainable large-scale, systems-level CQI is for an individual athletic trainer. From a behavioral change perspective, we are asking athletic trainers to equivocally overtake a mountain with no training. Our goal is to make CQI achievable for each athletic trainer in their own system, on their own terms. Some may question this philosophy, but because we are relative infants in this world of quality improvement, we propose an alternative.

Forms of CQI can vary, which may cause confusion, especially since formal training has been omitted in athletic training education to this

Copyright $(\subsetneq$ by Indiana State University All rights reserved. ISSN Online 2577-8188 point. Currently, a majority of the literature that exists in athletic training that focuses on CQI involves broad-level, large systems process improvement. Here, practicing athletic trainers serve to enter data into large databases such as the Athletic Training Practice-Based Research Network (ATPBRN); High School Reporting Information Online (High School RIO), National Athletic Treatment, Injury, and Outcomes Network (NATION); or NCAA Injury Surveillance Program. This evidence and information is meaningful and informs clinical practice in a way that can help us align our practice with best evidence. But, this asks athletic trainers not to reflect on their own practice or system, but to enter data to inform the larger profession. Meaningful, but not the fuel necessary to create change within their own practice.

There is a need for athletic trainers to share their experiences and data that they gather both in individual and systems level CQI processes. By sharing these experiences through dissemination, other athletic trainers can become aware of these individual CQI processes and improve their own practice. This identification and initial process improvement at the individual level is what will aid in athletic trainers becoming involved in process improvement within their organization at a system-level (Figure 1). Imagine an athletic trainer at a secondary school performs a small scale improvement project with a specific patient panel that they provide care for. They implement incremental change and track outcomes to make data driven decisions on the improvement project. This athletic trainer can then share their findings with another athletic trainer at the secondary school or at a similar school within the same system (e.g. healthcare system). They collaborate to expand the project. This shared project can then continue to grow between schools and eventually become a 


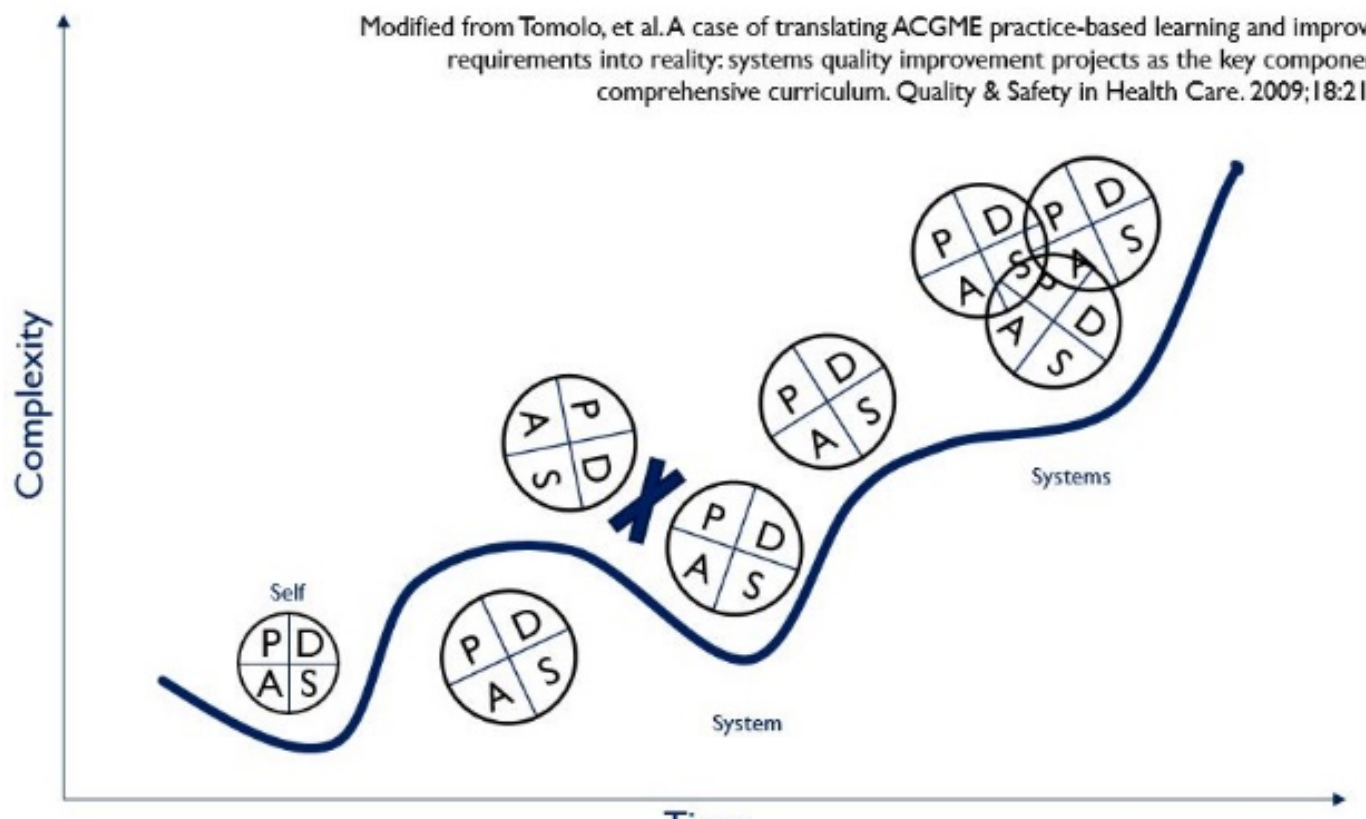

Time

Figure 1. Translation of Individual PDA Cycles to Systems-Level Approach

project that is implemented within the whole system. This is the eventual goal of CQI on the system-level. However, these progressive steps remain grounded in individual action.

Systems-based evaluation of clinical outcomes is the pinnacle of CQI, but there are many different frameworks, theories, or approaches to CQI in health care, most of which require action down to an individual level. Regardless of the patient care or process that is the target for improvement, individual actions will lead to overall, sustainable change within the system. It is these individual actions that can build upon one another, spread across multiple providers that can lead to larger process improvement and larger change. This initiation of CQI at an individual level can fuel the momentum into larger systems-level change.

There are many different CQI practices that athletic trainers can begin to implement on either an individual or systems-level. We have summarized a small portion of these in Table 1 to help begin to expose athletic trainers to these methods. Of particular interest within athletic training is the practice of checklist or standard work. By creating tools such as checklists for the processes within an athletic training clinic individual athletic trainers can help mitigate errors or make requirements explicit can help ensure quality of care. Further, by standardizing the processes or the work in individual clinics athletic trainers can ensure that work is done in a consistent way, leading to improvements in care.

With the addition of quality assurance in the CAATE Standards as well as the push for CQI in health care it is important we continue to disseminate the findings of athletic trainers from various settings using various $C Q$ methodologies. Therefore we are excited to announce the expansion of our Quality Improvement Section to include more methods than the Model of Improvement (Plan, Do, Study, and Act (PDSA) cycle) to include various $C Q I$ methodologies examining improvements in practice. Readers can find the new expanded section at our Manuscript Guidelines. We encourage authors to consider submitting their work in CQI for consideration for publication to continue to disseminate their experiences and help other athletic trainers learn and engage with improvement measures. 
Table 1. Continuous Quality Improvement Practices

\begin{tabular}{|c|c|}
\hline Tool & Brief Description and When to Use \\
\hline Affinity Diagram ${ }^{1}$ & $\begin{array}{l}\text { Affinity diagrams are the organized output of brainstorming with a group } \\
\text { of individuals. Affinity diagrams can be used when: } \\
\text { - A problem must be solved at all costs } \\
\text { - An easy solution is not found } \\
\text { - Time is needed to analyze the problem } \\
\text { - Participation of individuals promotes mutual understanding }\end{array}$ \\
\hline Waste Reduction ${ }^{2}$ & $\begin{array}{l}\text { Waste reduction is a strategy to improve the function of a system by } \\
\text { eliminating waste. Common examples of where waste can be found } \\
\text { include overproduction (e.g. unnecessary referrals), waiting, unnecessary } \\
\text { processing, staff movement, defects, transportation, and inventory. }\end{array}$ \\
\hline Checklist $^{3}$ & $\begin{array}{l}\text { The idea of a checklist is a simple tool. Critical quality control steps are } \\
\text { sometimes overlooked without checklists. Many healthcare functions } \\
\text { benefit from the use of checklists which makes explicit the requirements } \\
\text { for quality. A good checklist assures that the work has been done } \\
\text { correctly and completely. }\end{array}$ \\
\hline Standard Work ${ }^{4}$ & $\begin{array}{l}\text { Good quality requires that work be done in a consistent way. } \\
\text { Interventions to develop a better way will only have an impact on } \\
\text { practice if the new practice results in change that is consistent and } \\
\text { reliably implemented. Standard work is a written description which is } \\
\text { communicated and followed by all staff involved in a specific process. }\end{array}$ \\
\hline
\end{tabular}

\section{REFERENCES}

1. Lepley, CJ. Problem-solving tools for analyzing system problems: The affinity map and relationship diagram. J Nurs

Admin. 28(12). 1998. 44-50.

https://doi.org/10.1097/00005110199812000-00014.

2. Berwick, DM \& Hackbarth, AD. Elimiting Waste in US Health Care. JAMA.

2012;307(25):1513-1516.

https://doi.org/10.1001/jama.2012.362

3. Thomassen et al. Implementation of checklists in health care; learning from high-reliability organisations. Scand J

Trauma Resusc, Emerg Med.

2011;53(19). https://doi.org/10.1186/1757-7241-19-

53.

4. $\mathrm{Ng}, \mathrm{D}$ et al. Applying the Lean principles of the Toyota Production System to reduce wait times in the emergency department. CJEM. 2010;12(1):50-57. https://doi.org/10.1017/s14818035000 12021. 